\title{
Three Decades of Meningococcal Disease in the State of Santa Catarina, Brazil
}

\author{
Rubens C. B. Puricelli ${ }^{1}$, Emil Kupek ${ }^{2}$ \\ and Maria Helena Bittencourt Westrupp ${ }^{2}$
}

\author{
${ }^{1}$ Epidemiololical Vigilancy of Public Health Secretary of the \\ State of Santa Catarina, ${ }^{2}$ Department of Public Health, Federal \\ University of Santa Catarina, Florianópolis, SC, Brazil
}

\begin{abstract}
Consolidation of data on meningococcal disease surveillance for the state of Santa Catarina, Brazil, has provided new insight about the evolution of this disease during the period of 19712000. A descriptive epidemiological study, based on retrospective analysis of all cases of meningococcal disease notified in the state of Santa Catarina, linked the surveillance data from the Secretary of the State of Health, magnetic tape records and the data from the national surveillance of diseases of obligatory notification. Following World Health Organization guidelines, cumulative incidence exceeding five cases per 100,000 inhabitants was considered indicative of an epidemic. Official population data from the Fundação Instituto Brasileiro de Geografia e Estatística were used for the incidence denominator. During the 1971-2000 period, 7,893 cases and 1,354 deaths caused by meningococcal disease were reported. This corresponds to a mean of 263 cases and 45 deaths per year, with a mean incidence of 6.4 cases per 100,000 inhabitants and a fatality rate of $\mathbf{1 7 . 2 \%}$. Three distinct epidemiological periods were identified, two of which can be considered epidemic. Two of three distinct epidemiological periods were characterized by an epidemic of meningococcal disease, covering 20 of the 30 years analyzed. Identification of the epidemics and preventive actions, such as vaccination and health education, contributed to the reduction of morbidity and mortality due to this disease.

Key Words: Meningitis, meningococcal disease, surveillance, vaccination, Brazil.
\end{abstract}

Recent World Health Organization (WHO) estimates point to 300,000 cases and 30,000 deaths per year due to meningococcal disease worldwide, not counting the increases during epidemic years [1]. Despite the measures of prevention and control at our disposal, this disease is still inflicting a heavy toll in many countries all over the world.

During the 1990s, the state of Santa Catarina registered one of the highest incidences of meningococcal disease among Brazilian states [2]. From 1970 to 2000, the mean incidence per 100,000 inhabitants was 6.4 in Santa Catarina, compared to Received on 17 October 2003; revised 22 April 2004.

Address for correspondence: Dr.Rubens C.B. Puricelli. Rua Rui Barbosa, 544 Apto.51, Zip code: 88025-301 Florianópolis SC, Brazil. Phone 55 48-2281070. Fax 55 48-2218408 ext208; 55 48-2293615.E-mail: puricellirubens@ hotmail.com.br

The Brazilian Journal of Infectious Diseases 2004;8(3):241-48 (C) 2004 by The Brazilian Journal of Infectious Diseases and Contexto Publishing. All rights reserved.
3.5 for all of Brazil [3]. Earlier periods lack reliable data, especially on the serogroups causing this disease. This type of information started being collected only after large-scale epidemics due to $\mathrm{A}$ and $\mathrm{C}$ meningococci in the mid 1970s [4]. The state health authorities vaccinated the whole population of children under 15 years of age in response to this epidemic. Mass vaccination was also implemented against the epidemic at the end of the 1980s, caused by serogroup B meningococci, and in the mid 1990s, caused by serogroup C [5]. Based on consolidated data for the three decades, we argue that mortality and morbidity of meningococcal disease could have been considerably reduced had the vaccination took place earlier in the course of these epidemics.

The aim of this work was to describe the annual incidence of meningococcal disease in the state from 1971 to 2000, searching for a pattern of epidemics and likely reasons for their occurrence. 


\section{Materials and Methods}

A descriptive study of all notified cases of meningococcal disease was conducted, based on retrospective data for the period of 1971 to 2000. The case definition followed the criteria established by the Brazilian Ministry of Health, namely: clinical diagnosis compatible with meningococcal disease, clinical diagnosis and presence of Gram negative diplococci on bacterioscopy, identification of a specific antigen via electroimmunophoresis or latex agglutination, or identification of Neisseria meningitidis in culture [6]. The data bases examined for this purpose included the surveillance data and official reports from the Secretary of the State of Health, magnetic tape records and the data from the national surveillance system of diseases of obligatory notification (SINAN).

Following the WHO guidelines, cumulative incidence exceeding five cases per 100,000 inhabitants was considered indicative of an epidemic. Below this level, the risk of disease is considered low [7]. Most countries, Brazil included, report a low risk of meningococcal disease [8]. Official population data from the Fundação Instituto Brasileiro de Geografia e Estatística were used as the denominator for calculating incidence.

There were no data on the number of deaths caused by meningococcal disease for the period 1971-82, so case fatality was estimated at $21 \%$, based on the mean of the 1983 to 1987 period. Serogruping of meningococci has been done in the Central Public Health Laboratory (LACEN) in the state capital, Florianopolis, since 1981. Other laboratories started testing for meningococci since 1994, thus providing additional data for the diagnosis.

Disease incidence and related case fatality was analyzed comparing endemic versus epidemic periods, serogroups, age, sex, seasonal variations and clinical diagnosis.

\section{Results}

During the three decades, the state registered 7,893 cases and 1,354 deaths caused by meningococcal disease, with a mean of 263 cases and 45 deaths per year. The mean annual incidence was 6.4 per 100,000 inhabitants, with a mean case fatality of $17.2 \%$. Only $18.8 \%$ of all notified cases were serogrouped, with a predominance of groups $\mathrm{B}$ and $\mathrm{C}$ (Table 1).

Based on cumulative incidence per year, three distinct periods emerged (Figure 1). These are summarized as follows.

\section{First period: 1971-75 (Epidemic)}

During this period, 1,536 cases and 324 deaths due to meningococcal disease were registered. This corresponds to 307 cases and 65 deaths per year, with a mean annual incidence of 9.6 per 100,000 inhabitants and a fatality rate of $21.1 \%$ (Table 1 ). The epidemic reached its peak in 1974, when the incidence increased to 26.1 per 100,000 . In response to this epidemic, which started in 1973, a mass vaccination against serogroups $A$ and $C$ was conducted in 1975, using a bivalent AC vaccine. By the end of 1975, the number of cases and associated deaths was halved, suggesting effectiveness for this intervention.

\section{Second period: 1976-85 (Endemic)}

In this period, 1,176 cases and 242 deaths were registered, with a mean number of cases and deaths per year of 118 and 24, respectively (Table 1). Mean annual incidence was 3.2 per 100,000, ranging from 2.5 in 1979 to 4.0 in 1976 and 1985 . The case fatality rate was $20.6 \%$. Serogroup B was predominant, accounting for $83.9 \%$ of the cases analyzed, followed by $2.1 \%$ of serogroup C cases. However, only $7.9 \%$ of all notified cases were serogrouped in this period (Table 1).

\section{Third period: 1986-2000 (Epidemic)}

During this period, 5,181 cases and 788 deaths were caused by the disease, giving an annual mean of 345 cases and 53 deaths. Mean cumulative incidence was 7.4 per 100,000 per year, with a case fatality rate 
Table 1. Meningococcal disease in Santa Catarina, 1971-2000: Number of cases, incidence (Ic), number of deaths, case fatality $(\mathrm{CF})$ and serogrouping by year.

\begin{tabular}{|c|c|c|c|c|c|c|c|c|c|c|c|c|c|}
\hline \multirow[t]{2}{*}{ Period } & \multirow[t]{2}{*}{ Year } & \multirow[t]{2}{*}{ Cases } & \multirow[t]{2}{*}{ Ic } & \multirow[t]{2}{*}{ Deaths } & \multirow[t]{2}{*}{$\underset{(\%)}{\mathbf{C F}}$} & \multicolumn{2}{|c|}{$\begin{array}{l}\text { Serogroup } \\
\text { B }\end{array}$} & \multicolumn{3}{|c|}{ C other } & \multicolumn{3}{|c|}{$\begin{array}{l}\text { Total } \\
\quad \text { serogrouped }\end{array}$} \\
\hline & & & & & & $\mathbf{n}$ & $\%$ & n & $\%$ & $\mathbf{n}$ & $\%$ & $\mathrm{n}$ & $\%$ \\
\hline \multirow[t]{5}{*}{$1^{\text {st }}$ period } & 1971 & 46 & 1.5 & 10 & 21.0 & $\ldots$ & $\ldots$ & $\ldots$ & $\ldots$ & $\ldots$ & $\ldots$ & $\ldots$ & $\ldots$ \\
\hline & 1972 & 55 & 1.8 & 12 & 21.0 & $\ldots$ & $\ldots$ & $\ldots$ & $\ldots$ & $\ldots$ & $\ldots$ & $\ldots$ & $\ldots$ \\
\hline & 1973 & 195 & 6.1 & 41 & 21.0 & $\ldots$ & $\ldots$ & $\ldots$ & $\ldots$ & $\ldots$ & $\ldots$ & $\ldots$ & $\ldots$ \\
\hline & 1974 & 831 & 26.1 & 175 & 21.0 & $\ldots$ & $\ldots$ & $\ldots$ & $\ldots$ & $\ldots$ & $\ldots$ & $\ldots$ & $\ldots$ \\
\hline & 1975 & 409 & 12.6 & 86 & 21.0 & $\ldots$ & $\ldots$ & $\ldots$ & $\ldots$ & $\ldots$ & $\ldots$ & $\ldots$ & $\ldots$ \\
\hline Sub-total & & 1,536 & 9.6 & 324 & 21.1 & $\ldots$ & $\ldots$ & $\ldots$ & $\ldots$ & $\ldots$ & $\ldots$ & $\ldots$ & $\ldots$ \\
\hline \multirow[t]{10}{*}{$2^{\text {nd }}$ period } & 1976 & 134 & 4.0 & 28 & 21.0 & $\ldots$ & $\ldots$ & $\ldots$ & $\ldots$ & $\ldots$ & $\ldots$ & $\ldots$ & $\ldots$ \\
\hline & 1977 & 106 & 3.1 & 22 & 21.0 & $\ldots$ & $\ldots$ & $\ldots$ & $\ldots$ & $\ldots$ & $\ldots$ & $\ldots$ & $\ldots$ \\
\hline & 1978 & 95 & 2.7 & 20 & 21.0 & $\ldots$ & $\ldots$ & $\ldots$ & $\ldots$ & $\ldots$ & $\ldots$ & $\ldots$ & $\ldots$ \\
\hline & 1979 & 90 & 2.5 & 19 & 21.0 & $\ldots$ & $\ldots$ & $\ldots$ & $\ldots$ & $\ldots$ & $\ldots$ & $\ldots$ & $\ldots$ \\
\hline & 1980 & 116 & 3.2 & 24 & 21.0 & $\ldots$ & $\ldots$ & $\ldots$ & $\ldots$ & $\ldots$ & $\ldots$ & $\ldots$ & $\ldots$ \\
\hline & 1981 & 111 & 3.0 & 23 & 21.0 & 4 & 44.4 & 0 & 0.0 & 5 & 55.6 & 9 & 8.1 \\
\hline & 1982 & 98 & 2.6 & 21 & 21.0 & 14 & 77.8 & 1 & 5.5 & 3 & 16.7 & 18 & 18.4 \\
\hline & 1983 & 134 & 3.5 & 28 & 20.9 & 13 & 86.7 & 0 & 0.0 & 2 & 13.3 & 15 & 11.2 \\
\hline & 1984 & 133 & 3.3 & 18 & 16.8 & 21 & 91.4 & 1 & 4.3 & 1 & 4.3 & 23 & 17.3 \\
\hline & 1985 & 159 & 4.0 & 39 & 24.5 & 26 & 92.9 & 0 & 0.0 & 2 & 7.1 & 28 & 17.6 \\
\hline Sub-total & & 1,176 & 3.2 & 242 & 20.6 & 78 & 83.9 & 2 & 2.1 & 13 & 14.0 & 93 & 7.9 \\
\hline \multirow[t]{15}{*}{$3^{\text {rd }}$ period } & 1986 & 213 & 5.2 & 41 & 19.2 & 38 & 82.6 & 0 & 0.0 & 8 & 17.4 & 46 & 21.6 \\
\hline & 1987 & 274 & 6.6 & 64 & 23.4 & 42 & 95.5 & 0 & 0.0 & 2 & 4.5 & 44 & 16.0 \\
\hline & 1988 & 367 & 8.6 & 48 & 13.1 & 76 & 90.5 & 1 & 1.2 & 7 & 8.3 & 84 & 22.9 \\
\hline & 1989 & 423 & 9.7 & 73 & 17.3 & 101 & 90.2 & 2 & 1.8 & 9 & 8.0 & 112 & 26.5 \\
\hline & 1990 & 335 & 7.5 & 64 & 19.1 & 57 & 85.0 & 5 & 7.5 & 5 & 7.5 & 67 & 21.1 \\
\hline & 1991 & 294 & 6.5 & 36 & 12.2 & 54 & 87.1 & 7 & 11.3 & 1 & 1.6 & 62 & 21.1 \\
\hline & 1992 & 266 & 5.8 & 36 & 13.5 & 39 & 61.9 & 24 & 38.1 & 0 & 0.0 & 63 & 23.7 \\
\hline & 1993 & 383 & 8.2 & 54 & 14.1 & 60 & 57.1 & 43 & 41.0 & 2 & 1.9 & 105 & 27.4 \\
\hline & 1994 & 432 & 9.1 & 57 & 13.2 & 53 & 49.1 & 54 & 50.0 & 1 & 0.9 & 108 & 25.0 \\
\hline & 1995 & 536 & 11.1 & 62 & 11.6 & 88 & 43.8 & 110 & 54.7 & 3 & 1.5 & 201 & 37.5 \\
\hline & 1996 & 413 & 8.5 & 63 & 15.3 & 112 & 66.7 & 53 & 31.5 & 3 & 1.8 & 168 & 40.7 \\
\hline & 1997 & 362 & 7.3 & 60 & 16.6 & 68 & 60.2 & 43 & 38.1 & 2 & 1.8 & 113 & 31.2 \\
\hline & 1998 & 327 & 6.5 & 44 & 13.5 & 75 & 78.9 & 19 & 20.0 & 1 & 1.1 & 5 & 29.1 \\
\hline & 1999 & 314 & 6.2 & 50 & 15.9 & 53 & 79.1 & 14 & 20.9 & 0 & 0.0 & 67 & 21.3 \\
\hline & 2000 & 242 & 4.5 & 36 & 14.9 & 44 & 81.5 & 10 & 18.5 & 0 & 0.0 & 54 & 23.3 \\
\hline Sub-total & & 5,181 & 7.4 & 788 & 15.2 & 960 & 69.1 & 385 & 27.7 & 44 & 3.2 & 1,389 & 26.9 \\
\hline Total & & 7,893 & 6.4 & 1,354 & 17.2 & 1,038 & 70.0 & 387 & 26.1 & 57 & 3.9 & 1,482 & 18.8 \\
\hline
\end{tabular}

Note: A lack of data indicated by "..."

For the period 1971-1982, case fatality was estimated at 21\%, based on the mean of the 1983-1987 period. 
Figure 1. Annual incidence of meningococcal disease per 100,000 inhabitants and mass vaccination campaigns (vac.) against specific serogroups in Santa Catarina, 1971-2000.

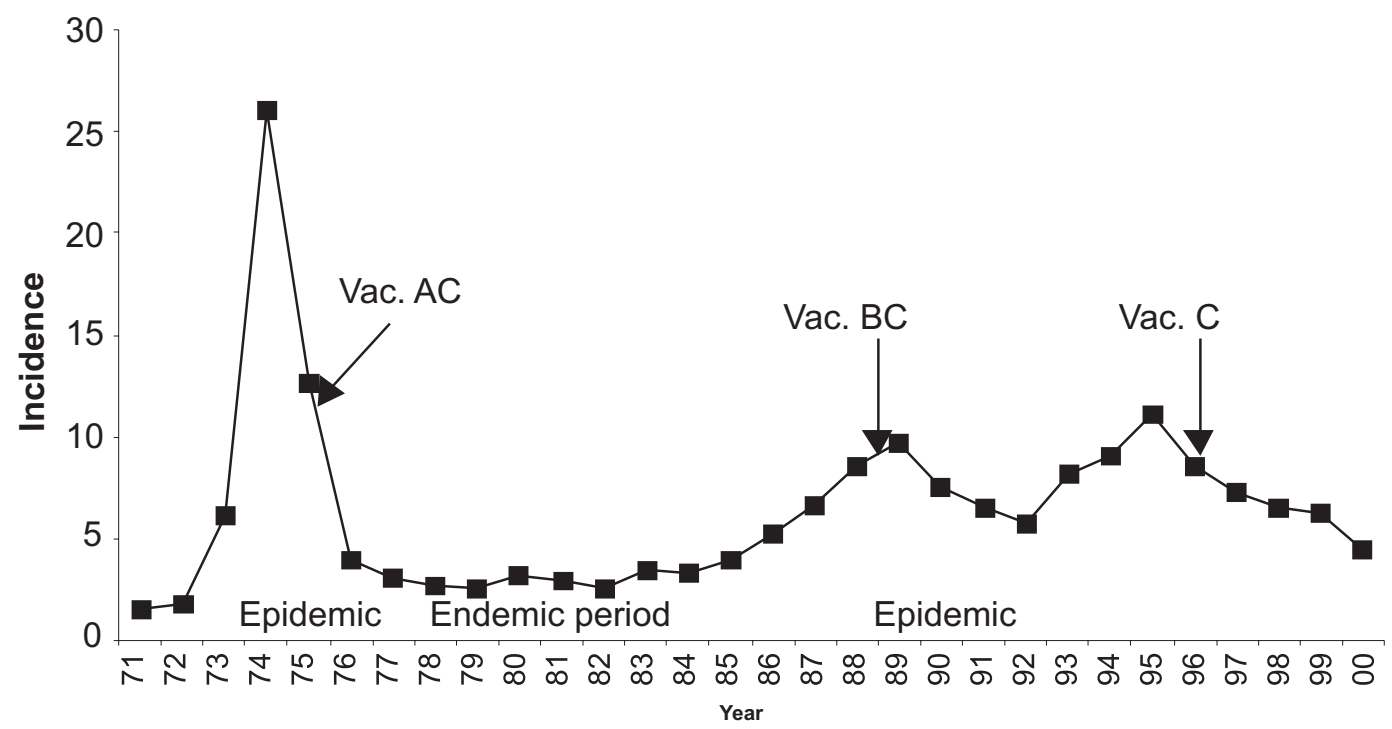

Figure 2. Number of cases of two major serogroups of meningococcal disease in Santa Catarina, 1971-2000.

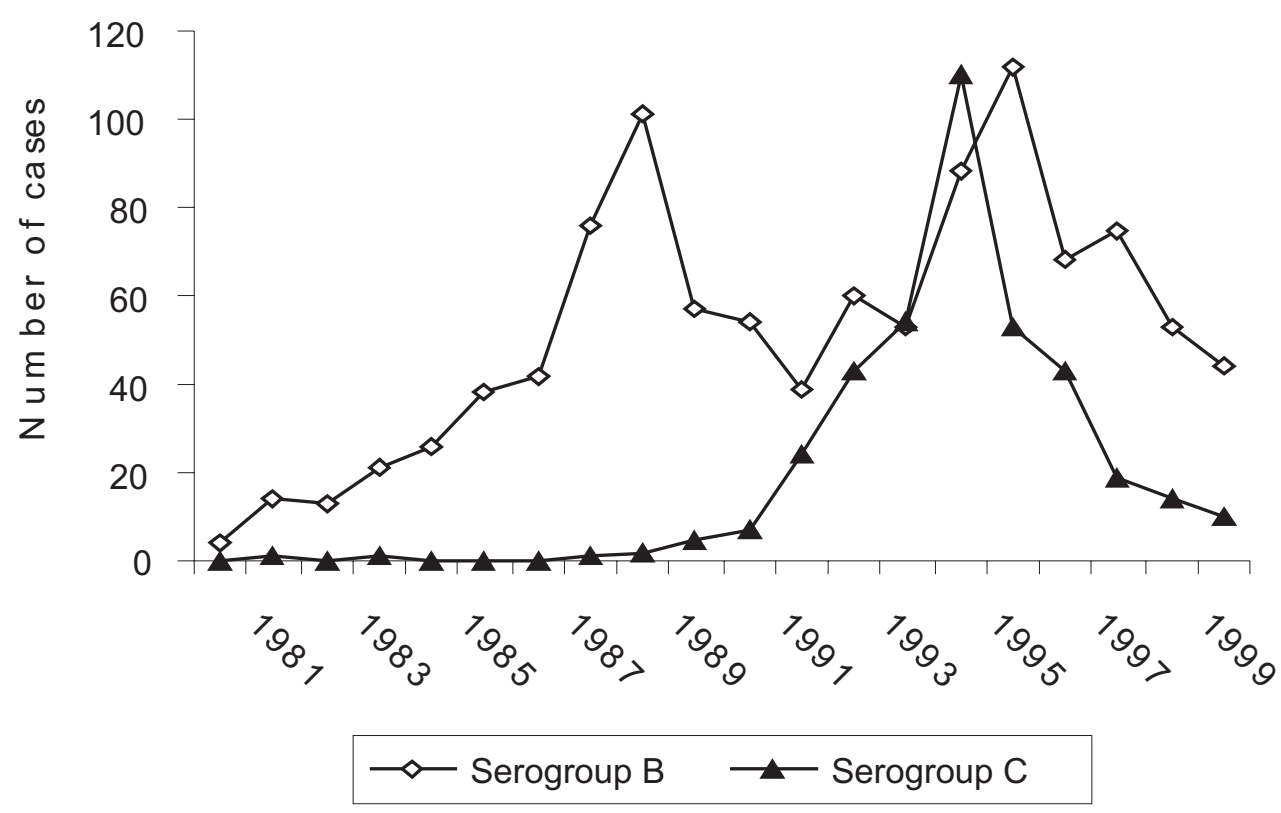


of $15.2 \%$. An average of $26.9 \%$ of all notified cases were serogrouped, indicating continuing predominance of B $(69.1 \%$ ) versus C (27.7\%) group (Table 1$)$.

Annual incidences per 100,000 for age groups $<5$, $5-14,15-49$ and 50 or older were $39.9,10.0,2.2$ and 1.1, respectively. Case fatality in these age groups was $17.6 \%, 8.2 \%, 11.7 \%$ and $35.7 \%$, respectively. At the peak of an epidemic in 1995, the incidence per 100,000 within these age groups was 56.7, 14.3, 2.8 and 1.1 , respectively, while case fatality registered $15.1 \%, 5.3 \% 6.8 \%$ and $28.6 \%$.

A comparison of 1995 incidence with that of the endemic 1976-85 period yielded a relative risk (RR) of 3.43 and a corresponding $95 \%$ confidence interval (CI) from 2.69 to 4.38 for children under five years of age. For the 5-14 age group, the comparison showed an RR of 4.10 (CI 2.81-5.97), and for the 15-50 age group the RR was 2.43 (CI 1.53-3.85). The oldest age group did not show a statistically significant change.

Meningococcal disease was significantly more likely to occur in winter $(2.8$ per 100,000$)$ when compared to summer (1.6 per 100,000), fall (1.7 per 100,000) or spring (1.9 per 100,000). Case fatality showed less seasonal variation, with $13.9 \%$ registered in summer, $14 \%$ in fall, $14.2 \%$ in winter and $14.5 \%$ in spring.

During the three decades, the incidence of meningococcal disease per 100,000 was 9.1 among men, compared to 7.9 among women. Case fatality was $12.6 \%$ among men and $15.2 \%$ among women. Serogroup B annual incidence per 100,000 was 1.6, with an associated case fatality of $7.1 \%$, compared to a serogroup $\mathrm{C}$ incidence of 1.1 and a case fatality of $16.7 \%$.

Among the $34.8 \%$ of all patients with meningococcal disease whose clinical diagnosis was meningitis, the case fatality was $6.5 \%$. This compares to $25.2 \%$ of all patients with meningococcemia, with $31.2 \%$ case fatality and $40.0 \%$ of all patients who had both meningitis and meningococcemia, with a case fatality rate of $10.4 \%$. The mean annual incidence was 3.0 cases of meningitis, 2.1 cases of meningococcemia and 3.4 of both meningitis and meningococcemia per 100,000 inhabitants.

\section{Discussion}

Although we cannot be sure that all cases of meningococcal disease were notified to the state health authorities, the gravity of this disease, which almost always requires hospitalization, makes underreporting unlikely. Perhaps a more serious limitation of the data is the low percentage of the cases that were serogrouped. Although there in no remedy for this problem in the past, increased efforts are needed to improve the quality of data in the future. Notwithstanding the limitations, the consolidated data for the 1971 to 2000 period are a significant improvement over the fragmented sources available beforehand.

During two thirds of this three-decade period, there was an epidemic of meningococcal disease in the state (Figure 1), thus it was one of the most serious public health problems. During this 30-year period, the mean annual incidence per 100,000 inhabitants was 6.4 in Santa Catarina, almost twice the 3.5 registered for Brazil as a whole [3]. On the other hand, the case fatality rate was lower in Santa Catarina (17.2\%) than for Brazil (20\%).

During the endemic period from 1976 to 1985 , the annual disease incidence per 100,000 ranged from 2.5 to 4.0 , with a mean value of 3.2 cases. This is more than twice the national average of 1.5 per 100,000 for the same period [3], indicating an elevated risk even during the endemic period.

The peak of the first epidemic period (1971-1975) was the year 1974 when disease incidence reached 26.1 per 100,000, giving rise to a mass vaccination program against serogoups $\mathrm{A}$ and $\mathrm{C}$ in the following year. By the end of the year, both incidence and case fatality were halved, indicating the effectiveness of this intervention.

Differently from the first epidemic period, during the third epidemic period (1986-2000) there was a slower increase in the number of cases, and there was a bimodal distribution, with peaks in 1989 and 1995 (Figure 1). The number of cases of meningococcal disease leaped from an endemic level in 1985 to an epidemic level of 5.2 per 100,000 in the following year, 
similar only to the epidemic level of the 1970s. After reaching an incidence of 11.1 per 100,000 inhabitants in 1995, a decreasing trend was observed for the rest of this period.

During the 1986-2000 period, two mass vaccination campaigns were implemented. The first took place in 1989-90, after three years of epidemic caused by serogroup B meningococci (Figure 2). The "VaMengoc BC" vaccine was applied to 232,022 children from three months to seven years of age, residing in 20 municipalities most affected by the disease. The vaccine efficacy for children over four years of age was estimated at 78\% [9]. A decreasing trend in disease incidence that started after this vaccination effort continued until 1992. In 1993, however, there was a $44 \%$ rise in the number of new cases compared to the previous year, and the incidence reached 8.2 per 100,000. As serogroup C meningococci were responsible for this epidemic (Figure 2), another mass vaccination against this serogroup was implemented, but only in 1996, three years after the start of the epidemic. Nearly all children and adolescents residing in the state - 976,389 of them - were vaccinated with anti $\mathrm{C}$ monovalent vaccine, produced in the BioManguinhos laboratory in Rio de Janeiro. Unfortunately, it took an incidence of more than 10 new cases per 100,000 inhabitants in the previous year to start off this vaccination program. The vaccine effectiveness was estimated at $93.1 \%$ [5].

It seems that both vaccination campaigns should have been implemented as soon as the rise in incidence passed the epidemic level, instead of after a three-year delay. This could have avoided a considerable number of new cases, as the vaccines were effective. Although children under five years of age are most at risk for meningococcal disease during endemic periods [10], the risk also increases considerably for a much larger segment of population during an epidemic, including adolescents and young people in general. For example, it was the 5-14 year-old age group that had the largest increase in disease incidence when the epidemic years were compared to the endemic ones in the state of Santa Catarina. On the other hand, no such finding was found for the age group of 50 years and over.
Case fatality was inversely related to incidence, reaching its lowest value of $11.6 \%$ at the peak of the epidemic in 1995. This could be due to a higher alert level of both the general population and of medical professionals, thus providing the benefits of timely diagnosis and treatment. An analysis of the 1994-2000 period, for which reliable information on the age of the patients was available, showed that case fatality is elevated at age extremes, i.e. children and those age 50 years and over. Case fatality was lower for the 514 year-old age group, a finding similar to that observed in the city of Campinas in the state of São Paulo [11].

In concordance with our findings, serogroup $C$ was found to be associated with increased case fatality compared to serogroup B meningococci in other studies [12-14]. However, a high case fatality of $16.7 \%$ for the cases not serogrouped and a low percentage of serogrouped cases limit this comparison. There is a pressing need to amplify the range of laboratory investigation to include not only cerebrospinal fluid, but also blood, thus allowing a more precise analysis of the impact of serogroup on disease evolution.

Seasonal variations in meningococcal disease frequency were observed in a number of studies $[13,15,16]$, indicating a significant increase in incidence during winter months. This could be related to higher probability of transmission of meningococci in closed ambients, with a high contact density between people and a higher prevalence of respiratory infections during winter. On the other hand, case fatality did not vary significantly.

The higher incidence of meningococcal disease among men compared to women was also found in the municipality of São Paulo [15]. This could be related to a higher contact rate with meningococci carriers among men, due to more time spent outside the residence and their higher mobility in general, largely as a function of their economic activities [17]. However, other authors did not find significant sex differences in disease incidence [16]. In Santa Catarina, case fatality was higher for women $(15.2 \%)$ compared to men (12.6\%). It is difficult to determine whether this was due to the inverse relationship between incidence and case fatality in general or due to some other specific factors. 
According to WHO, observed case fatality is about $10 \%$ for meningitis patients, if adequately treated, but it can reach $50 \%$ in the case of meningococcemia [10]. In Santa Catarina, meningococcemia caused the highest case fatality rate $(31.2 \%)$ among patients with meningococcal disease. As almost two thirds of patients with meningococcal disease had meningococcemia, this is a likely reason for the elevated overall case fatality of $17.7 \%$. In addition, underutilization of blood analysis for serogrouping increased the chance of wrongly diagnosing meningococcemia, when in fact other causative agents were involved. Once again, this underlines the need for wider use of blood analysis in diagnosing meningococcal disease.

The importance of controlling serogroup B meningococci has clearly increased since the 1980s (Figure 2). However, though their incidence in Santa Catarina already reached epidemic levels in 1986, mass vaccination against this serogroup occurred only at the end of the decade. The epidemic started in São Paulo and spread to the rest of the country by 1988 [18], including Santa Catarina as one of the most affected states [19]. However, the federal health authorities officially declared the epidemic only in June 1989, including the state capital Florianopolis and two other cities (Blumenau and Joinville) as high-risk areas [18].

Although serogroup B was predominant in Santa Catarina in the 1990s, the participation of serogroup C increased more rapidly from $7.5 \%$ at the beginning of the decade to $54.7 \%$ in 1995 . This rising trend was reverted after a mass vaccination campaign against this serogroup in 1996. Had it been done in 1986, when it already had reached epidemic levels, a considerable reduction in morbidity and mortality could have taken place much earlier than it did. It seems prudent to conclude that all three vaccination campaigns in Santa Catarina should have occurred several years earlier when specific serogroup incidence reached the epidemic threshold indicated by WHO, i.e. five new cases per 100,000 inhabitants per year.

Current surveillance of meningitis in Santa Catarina is a significant improvement compared to past efforts, principally in terms of laboratory facilities and information links between local and state health authorities. The capacity to respond promptly to an outbreak of meningococcal disease in a restricted area has been demonstrated recently [20]. We hope that such interventions can prevent future epidemics in the state, leaving mass vaccination campaigns against meningococcal disease in the past.

\section{References}

1. Organizacion Mundial da la Salud. Vacunas e Imunizacion: situacion mundial. Genebra: Organizacion Mundial da la Salud, 1997.

2. Secretaria de Estado da Saúde de Santa Catarina. As meningites no Estado de Santa Catarina. Florianópolis: Secretaria de Estado da Saúde de Santa Catarina, Diretoria de Vigilância Epidemiológica, 2001.

3. Ministério da Saúde. Situação epidemiológica das meningites e da doença meningocócica no Brasil. Brasília: Ministério da Saúde, Fundação Nacional de Saúde, Centro Nacional de Epidemiologia, Grupo de Trabalho Meningite, 2001.

4. Gama S.G.N., Marzochi K.B.F., Silveira Filho G.B. Caracterização epidemiológica da doença meningocócica na área metropolitana do Rio de Janeiro, Brasil, 1976 a 1994. Rev Saúde Pública 1997;31(3):254-62.

5. Kupek E., Puricelli R.C.B., Westrupp M.H.B. Effectiveness of a mass immunization campaign against serogroup $\mathrm{C}$ meningococci in children in the federal state of Santa Catarina, Brazil. Braz J. Infect Dis 2001;5(6):324-31.

6. Ministério da Saúde. Guia de Vigilância Epidemiológica. Brasília: Ministério da Saúde, Fundação Nacional de Saúde, Centro Nacional de Epidemiologia, 1998.

7. World Health Organization Working Group. Control of epidemic meningococcal disease. Lyon: Fondation Marcel Mérieux, 1995.

8. Frasch C.E. Immunization against Neisseria meningitidis. In: Easmon, C.S.F. \& Jeljaszewicz, J. eds. Immunization against bacterial disease. London: Academic Press, 1983.

9. Costa E.A., Martins H., Klein C.H. Avaliação da proteção conferida pela vacina antimeningocócica BC no Estado de Santa Catarina, Brasil, 1990/92. Rev Saúde Pública 1996;30(5):460-70.

10. World Health Organization. Control of epidemic meningococcal disease: practical guideline. Geneva: World Health Organization, 1998.

11. Kemp B. Aspectos epidemiológicos e diagnóstico laboratorial da doença meningocócica no Município de Campinas/SP, no período 1988 a 1993 [M.Sc. thesis]. São Paulo: Faculdade de Saúde Pública, Universidade de São Paulo, 1994. 
12. DeWalls P., Dionne M., Douville-Fradet M. et al. Impact of a mass immunization campaign against serogroup $\mathrm{C}$ meningococcus in the province of Quebec, Canada. Bull World Health Organ 1996;74(4):407-11.

13. Whalen C.M., Hockin J., Ryan A., Fraser A. The changing epidemiology of invasive menigococcal diseases in Canada, 1985 through 1992. JAMA 1995;273:(5):645-51.

14. Krízova P., Musilek M. Changing epidemiology of meningococcal invasive disease in the Czech Republic caused by new clone N.m.C. Cent Eur J Public Health 1995;4:189-94.

15. Iversson L.B. Aspectos epidemiológicos da meningite meningocócica no município de São Paulo (Brasil), no período 1968-1974. Rev Saúde Pública 1976;10:1-16.

16. Pinner R.W., Gellin B.G., Bibb W.F., et al. Meningococcal disease in the United States -1986. J Infect Dis 1991; 164:368-74.

17. Peltola H. Meningococcal disease: still with us. Rev Infect Dis 1983;5(1):71-93.

18. Amato Neto V., Baldy J.L.S., Silva L.J. Imunizações efetuadas circunstancialmente no Brasil. São Paulo: Sarvier, 1991.

19. Ministério da Saúde. Doença meningocócica no Brasil: avaliação do primeiro semestre de 1988. Boletim Nacional de Epidemiologia 1988;1(8)1-12.

20. Puricelli R.C.B., Rodrigues M.I.S., Gandin N.I., Bertoncini R.C. Bloqueio vacinal como estratégia para o controle de epidemia pelo meningococo do sorogrupo $\mathrm{C}$, em Santa Catarina, 2001. URL: http://Funasa.gov.br/ epi/ epi00.htm [accessed September 15, 2003]. 